\title{
The quality of school lunch consumed reflects overall eating patterns in 11-16-year-old schoolchildren in Finland
}

\author{
Tanja Tilles-Tirkkonen ${ }^{1, *}$, Saara Pentikäinen ${ }^{2}$, Jenni Lappi ${ }^{1}$, Leila Karhunen ${ }^{1}$, \\ Kaisa Poutanen ${ }^{1,2}$ and Hannu Mykkänen ${ }^{1}$ \\ 'Department of Clinical Nutrition, Food and Health Research Centre, University of Eastern Finland, \\ PO Box 1627, 70211 Kuopio, Finland: ${ }^{2}$ VTT Technical Research Centre of Finland
}

Submitted 12 November 2010: Accepted 10 May 2011: First published online 14 July 2011

\begin{abstract}
Objective: To explore how the quality of school lunch consumed reflected overall eating patterns in school-aged children.

Design: Children filled in an Internet-based questionnaire about their eating patterns. The children were then divided into balanced and imbalanced school lunch eaters on the basis of their responses in the questionnaire. A balanced school lunch consisted of, by the definition used in the present study, a main dish, salad and bread.

Setting: Eleven primary schools and one middle school in eastern Finland.

Subjects: A total of 531 schoolchildren (247 boys and 284 girls) aged 11-16 years.

Results: The school lunch was balanced in $46.5 \%$ of children. Eating a balanced school lunch was associated with overall healthier eating patterns outside school. Children who ate a balanced school lunch had more regular meal times and consumed healthier snacks. They ate fruit or berries and vegetables, dairy products and wholegrain foods more often, consumed fewer salty snacks, pizzas, meat pies and drank fewer soft drinks and energy drinks. Their eating patterns at home were also healthier, with vegetables being offered at every family dinner and fruit being offered daily, whereas soft drinks were offered seldom.

Conclusions: The choices made by children in their school lunch reflect the overall eating patterns among school-aged children. Eating a balanced school lunch is associated with more regular meal patterns, the availability of healthier foods at home and an overall healthier diet, suggesting that healthy eating patterns are learnt at home.
\end{abstract}

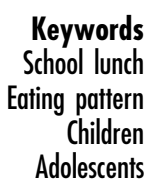

In Finland, the idea of a free school lunch was introduced during the Second World War. Children's poor nutrition emerged as a social and public health problem, when war led to food shortages and brought women into the labour force. Finland was the first country in the world to serve free school lunches when free school catering started in $1948^{(1)}$.

Nowadays, free school lunches are offered to all schoolchildren undergoing basic education each school day ${ }^{(1,2)}$. According to recommendations, the school lunch must be properly organized, supervised and nutritionally balanced. It is also an important part of nutritional education, aiming at demonstrating to children how to put together a nutritionally balanced meal. The Finnish National Nutrition Council has issued recommendations for school meals ${ }^{(2)}$. According to these recommendations, the school lunch should cover one-third of the child's daily energy intake and should be composed according to the plate model. Half of the plate should be filled with vegetables, one-quarter with potatoes, rice or pasta and the last quarter with meat, chicken or fish. The school lunch should also include bread with vegetable oil-based margarine and skimmed or semi-skimmed milk or sour milk. The school lunch is considered balanced when all these components of a meal are included.

Studies on school lunches are rather scarce, since free hot meals at school are common only in a few Western countries such as Finland and Sweden. Raulio et al. ${ }^{(3)}$ examined the association of lunch-eating patterns with overall food habits and nutrient intakes in school-aged children in Finland. Consumption of school lunches was associated with higher consumption of vegetables, fruit, rye bread, milk, sour milk and cheese. On the other hand, skipping school lunches was associated with higher consumption of French fries, potato chips, hamburgers, pizza, meat pies, ice cream, candy and chocolate. Hastert and Babey ${ }^{(4)}$ examined the relationship between dietary behaviour and frequency of eating packed lunches among adolescent students. They observed that adolescents who 
brought a packed lunch from home each school day ate fast food, soft drinks, fried potatoes and high-sugarsweetened foods less frequently and ate fruit and vegetables more often compared with adolescents who never consumed packed lunches at school. In general, children and adolescents in Finland and in many other countries consume fewer fruit and vegetables than recommended, and their diet contains considerably large amounts of candies, soft drinks, cookies and salty snacks ${ }^{(5,6)}$. Consequently, the intake of dietary fibre is considerably low and that of sugar significantly high. High consumption of soft drinks, energy drinks and candies is associated with overweight $^{(7-9)}$, whereas consumption of vegetables and fruit is inversely associated with overweight ${ }^{(10,11)}$.

High meal frequency is positively associated with an overall healthier diet ${ }^{(12)}$. For example, those consuming meals more frequently also consume vegetables more often ${ }^{(13,14)}$. In addition, high regularity of eating breakfast was found to be positively associated with a healthier diet, such as lower consumption of sweet and salty snacks, soft drinks and juices ${ }^{(15)}$. Several studies have also observed an association between frequency of family meals and healthy diet $^{(16-18)}$. High frequency of family meals has been found to be inversely associated with overweight ${ }^{(18-20)}$.

The aim of the present study was to explore the manner in which the quality of the school lunch consumed reflected the overall eating pattern among school-aged children.

\section{Methods}

\section{Data collection}

Data for the present study were collected in the spring of 2010 from all primary and middle schools in Sotkamo, a town of approximately 11000 inhabitants in eastern Finland. There are eleven primary schools and one middle school in the town. Several of the primary schools are small village schools. The study was conducted after obtaining permission from the school principals and with the consent of the parent or guardian.

Children in grades 5-9 (aged 11-16 years) were asked to fill in an Internet-based questionnaire about their eating patterns and consumption of different kinds of food. They were also asked to report their height and body weight. A total of 531 of 629 schoolchildren completed the questionnaire. It was filled in at school and the teachers assisted the children when needed.

The questionnaire consisted of two parts. Part 1 contained thirteen questions about eating patterns and part 2 contained thirty-seven questions about the frequency of consumption of different food items. Of the questions, forty-seven were structured and three were open. Some of the questions were derived from the questionnaires used in the Health Behavior of School Aged Children study conducted by $\mathrm{WHO}^{(21)}$ and some from the School Health Promotion Study conducted by the National Institute for Health and Welfare in Finland ${ }^{(22)}$.
Part 1 included questions about the type (breakfast (more than a glass of milk or juice), lunch, afternoon snack, dinner, evening snack) and frequency (never, 1-2 times/week, 3-4 times/week, daily) of meals consumed during school days and weekends, as well as about the meal components (main dish, salad, bread, margarine, milk/sour milk) consumed in a typical school lunch. The question about the reasons for skipping school lunch included the following options: not hungry; does not like the food; queue too long; noisy environment; friends do not eat; ate during home economics; eats packed lunch; spends lunch time doing something else; eats somewhere else; and some other reason. Open questions were related to opinions about the school lunch and how it should be improved.

The questionnaire also evaluated the frequency ( $\geq 4$ times/d, 3 times/d, 1-2 times/d, do not eat snacks daily, hardly ever eats snacks) and type (candies or chocolate, fruits or berries, vegetables, ice cream, buns, cookies or doughnuts, salty snacks, bread, soft drinks or energy drinks, dairy products, something else) of typical snacks. Family eating patterns were evaluated by questions including statements about shared meals, regular meal times, availability of vegetables, fruit, salty snacks, sweet snacks and soft drinks, the possibility of influencing food choices and children taking part in cooking. The frequency of shared family meals was evaluated by the following scale: never; rarely (1-2 times/week); 3-4 times/week; almost every day (5-6 times/week); and daily.

Part 2 evaluated the frequency of consumption of foods in the following groups: fast foods; cereal products; dairy products; salty and sweet snacks; vegetables and fruit; and drinks. The frequency options were from never to several times per day.

Children were classified as normal weight or overweight according to international BMI cut-off points for children ${ }^{(23)}$. According to the Centers for Disease Control and Prevention criteria, children with BMI $<5$ th percentile were classified as underweight ${ }^{(24)}$.

\section{Analysis of the eating pattern of school lunches}

Children were divided into 'balanced' and 'imbalanced' school lunch eaters. Only forty-five of $514(8.8 \%)$ children ate all components of a meal meeting the criteria of a well-balanced school lunch set by the Finnish National Nutrition Council ${ }^{(2)}$ (Table 1). Because of this small number of respondents considered as well-balanced school lunch eaters, a less-strict definition was used to indicate a balanced school lunch, reflecting the nutritional quality of children's school lunches (Table 1). In the present study, a school lunch was considered to be balanced if it included always or often (3-4 school days/ week) a main dish, salad and bread. Those schoolchildren who never or rarely ate a school lunch containing all the above-mentioned components were considered as 'imbalanced eaters'. Eating patterns and 
Table 1 Definition of a balanced school lunch according to the Finnish National Nutrition Council ${ }^{(2)}$ and by the present study

\begin{tabular}{lcc}
\hline $\begin{array}{l}\text { Components of } \\
\text { the school lunch }\end{array}$ & $\begin{array}{c}\text { Finnish National } \\
\text { Nutrition Council }\end{array}$ & $\begin{array}{c}\text { The present } \\
\text { study }\end{array}$ \\
\hline Main dish & $\mathrm{X}$ & $\mathrm{X}$ \\
Salad & $\mathrm{X}$ & $\mathrm{X}$ \\
Bread & $\mathrm{X}$ & $\mathrm{X}$ \\
Margarine & $\mathrm{X}$ & - \\
Milk or sour milk & $\mathrm{X}$ & - \\
\hline
\end{tabular}

consumption of different foods were compared between those who regularly ate a balanced school lunch and those who did not.

\section{Statistical analyses}

Statistical analyses were conducted using the Statistical Package for the Social Sciences statistical software package for Windows version $14 \cdot 0$ (SPSS Inc., Chicago, IL, USA). Frequencies generated by cross-tabulations were tested using the $\chi^{2}$ test for statistical significance. In a few cases, the number of observations in a cell was too low to fulfil the minimum requirements for normal distribution of the $\chi^{2}$, and therefore the non-parametric version of the $\chi^{2}$ was used (i.e. Fisher's Exact test). $P$ value $<0 \cdot 05$ was regarded as statistically significant.

If needed, the answer options described above were combined for statistical analyses to increase the number of respondents in each subgroup.

\section{Results}

The final study sample consisted of 531 schoolchildren, of whom $53.5 \%$ were girls and $46.5 \%$ were boys. The prevalence of overweight or obesity among the children was $20 \cdot 8 \%$, and $4.5 \%$ of children were underweight. Altogether, 514 children could be classified as either wellbalanced or imbalanced school lunch eaters: $46.5 \%$ ate a balanced lunch and $53.5 \%$ an imbalanced lunch. Of the balanced eaters, $59 \%$ were girls and $41 \%$ were boys; this difference was significant $(P=0 \cdot 037)$. Girls ate salad in school lunches significantly more often than did boys. Altogether, $75 \%$ of girls and $63 \%$ of boys ate vegetables often in their school lunches $(P=0 \cdot 005)$. Consumption of a main dish and bread did not differ between girls and boys. The balanced and imbalanced eaters did not differ in age or in prevalence of overweight, obesity or underweight. The characteristics of the study population are presented in Table 2.

\section{Meal frequency}

Most of the children had regular meal frequency on school days and on weekends. Altogether, $61 \%$ of the children ate breakfast (more than a glass of milk or juice) every day but $24 \%$ had breakfast rarely (1-2 times/week)
Table 2 Descriptive characteristics of the study population

\begin{tabular}{lrrrrr}
\hline & \multicolumn{2}{c}{$\begin{array}{c}\text { Balanced eaters } \\
(n \text { 239) }\end{array}$} & & \multicolumn{2}{c}{$\begin{array}{c}\text { Imbalanced eaters } \\
(n \text { 275) }\end{array}$} \\
\cline { 2 - 3 } \cline { 6 - 7 } & $n$ & $\%$ & & $n$ & $\%$ \\
\hline Female & 141 & $59 \cdot 0$ & & 137 & $49 \cdot 8$ \\
Male & 98 & $41 \cdot 0$ & & 138 & $50 \cdot 2$ \\
5th grade & 40 & $16 \cdot 8$ & & 30 & $10 \cdot 9$ \\
6th grade & 39 & $16 \cdot 3$ & & 50 & $18 \cdot 2$ \\
7th grade & 54 & $22 \cdot 6$ & & 67 & $24 \cdot 4$ \\
8th grade & 61 & $25 \cdot 5$ & & 78 & $28 \cdot 4$ \\
9th grade & 45 & $18 \cdot 8$ & & 50 & $18 \cdot 2$ \\
Normal weight & 183 & $77 \cdot 5$ & & 194 & $72 \cdot 9$ \\
Overweight & 42 & $17 \cdot 8$ & & 60 & $22 \cdot 6$ \\
Underweight & 11 & $4 \cdot 7$ & & 12 & $4 \cdot 5$ \\
\hline
\end{tabular}

tThose schoolchildren who always or often (at least 3-4 school days/week) ate a school lunch containing a main dish, salad and bread.

$\ddagger$ Those schoolchildren who never or rarely ate a school lunch containing a main dish, salad and bread.

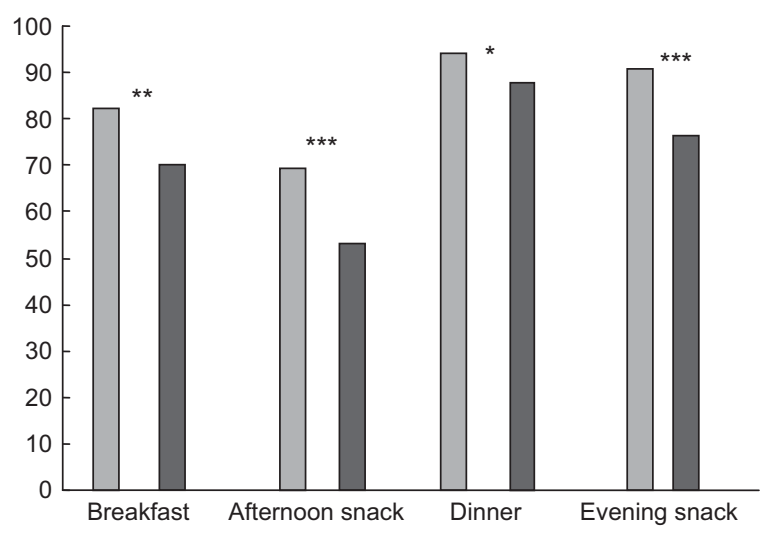

Fig. 1 Meals consumed $3-4 \mathrm{~d} /$ week or more often among balanced $(\square)$ and imbalanced $(\square)$ school lunch eaters on school days (percentage of balanced and imbalanced eaters; $n$ 497-514). Frequencies were generated by cross-tabulations using the $\chi^{2}$ test for statistical significance $\left({ }^{\star} P<0.05\right.$, $\left.{ }^{\star \star} P<0.01,{ }^{\star \star \star} P<0.001\right)$

or never on school days. Altogether, $82 \%$ of the children ate lunch, $72 \%$ dinner and $56 \%$ an evening snack every school day. Breakfast and evening snack were eaten more often and lunch and dinner less often on weekends than on school days. Altogether, $71 \%$ of the children ate breakfast, 63\% lunch, $71 \%$ dinner and $70 \%$ evening snacks on weekends. Snacks were also eaten less often on weekends. A total of $58 \%$ of the children ate an afternoon snack daily or often on school days and 43\% on weekends. Eating a balanced school lunch was more strongly associated with regularity of meal times both on school days and on weekends than was eating an imbalanced school lunch. The meal frequencies of the balanced and imbalanced school lunch eaters on school days and weekends are presented in Fig. 1 and Table 3, respectively. Children who ate a balanced school lunch more often ate breakfast $(P=0 \cdot 001)$, an afternoon snack $(P<0 \cdot 001)$, dinner $(P=0 \cdot 017)$ and an evening snack $(P<0 \cdot 001)$ on school days than did children who consumed 
Table 3 Number of meals eaten during weekends among balanced ( $n$ 234-239) and imbalanced ( $n$ 263-274) school lunch eaters

\begin{tabular}{|c|c|c|c|c|c|c|c|}
\hline & \multicolumn{3}{|c|}{ Balanced eaters } & \multicolumn{3}{|c|}{ Imbalanced eaters } & \multirow[b]{4}{*}{$P$ value } \\
\hline & \multicolumn{3}{|c|}{ Number of meals eaten during weekends } & \multicolumn{3}{|c|}{ Number of meals eaten during weekends } & \\
\hline & 0 & 1 & 2 & 0 & 1 & 2 & \\
\hline & $\%$ & $\%$ & $\%$ & $\%$ & $\%$ & $\%$ & \\
\hline Breakfast & $5 \cdot 9$ & $15 \cdot 0$ & $79 \cdot 1$ & $8 \cdot 7$ & $24 \cdot 5$ & $66 \cdot 8$ & 0.008 \\
\hline Lunch & $11 \cdot 5$ & $20 \cdot 0$ & $68 \cdot 5$ & $14 \cdot 1$ & $20 \cdot 5$ & $65 \cdot 4$ & 0.657 \\
\hline Afternoon snack & $17 \cdot 0$ & $31 \cdot 0$ & $52 \cdot 0$ & $24 \cdot 3$ & $36 \cdot 2$ & $39 \cdot 5$ & 0.010 \\
\hline Dinner & $3 \cdot 0$ & $13 \cdot 2$ & $83 \cdot 8$ & $9 \cdot 7$ & $24 \cdot 3$ & $66 \cdot 0$ & $<0.001$ \\
\hline Evening snack & $2 \cdot 1$ & $18 \cdot 1$ & $79 \cdot 8$ & $8 \cdot 1$ & $27 \cdot 1$ & $64 \cdot 8$ & $<0.001$ \\
\hline
\end{tabular}

${ }^{*}$ Frequencies were generated by cross-tabulations using the $\chi^{2}$ test for statistical significance.

an imbalanced school lunch. In addition, on weekends, balanced school lunch eaters ate breakfast $(P=0 \cdot 008)$, an afternoon snack $(P=0 \cdot 010)$, dinner $(P<0 \cdot 001)$ and an evening snack $(P<0 \cdot 001)$ more often than did imbalanced school lunch eaters. The frequency of eating lunch on weekends did not differ between the groups.

The most common reasons for skipping school lunches were: the children did not like the foods offered (22\%); they were not hungry (14\%); they had already eaten during their home economics class (8\%); they felt that the eating environment was unpleasant (7\%); or their friends did not eat a school lunch (3\%). To improve school lunches, the children suggested that: it should be planned more according to the children's taste preferences; the lunch menu should be more variable; a larger variety of breads should be offered; fruit should be offered more often (e.g. as afternoon snacks); and vegetables should be offered as individual components instead of in mixed salads. They also wished to have more desserts, such as fruit or berry fool. The children reported that the eating environment should be pleasant and cosy, with background music, and that the foods should be served attractively.

\section{Snacking}

Most of the children (54\%) ate one to two snacks between main meals (breakfast, lunch, dinner and evening snack); $28 \%$ had three or more snacks per day and $16 \%$ did not eat any snacks. The frequency of snacking was the same among balanced and imbalanced school lunch eaters. Most of the children ate healthy snacks, such as bread (63\% of the children), dairy products (51\%) and fruit or berries (49\%). However, unhealthy snacks were also quite common: candies or chocolate (27\%) buns, cookies or doughnuts (27\%), soft drinks or energy drinks (20\%), ice cream (18\%) and salty snacks (11\%). Only $12 \%$ of the children ate vegetables as snacks. The balanced school lunch eaters consumed healthier snacks compared with imbalanced school lunch eaters. The snacks consumed most often by the balanced and imbalanced school lunch eaters are presented in Table 4 . The balanced school lunch eaters ate fruit or berries $(P<0.001)$ and dairy products $(P=0 \cdot 008)$ more often and salty snacks $(P=0 \cdot 026)$ less frequently. They also consumed fewer soft drinks or energy drinks $(P=0 \cdot 010)$ as snacks compared with the imbalanced school lunch eaters. The consumption of candies or chocolate, vegetables, ice cream, buns, cookies or doughnuts and bread did not differ between the groups.

\section{Family dinner and eating pattern at bome}

The majority of children (58\%) had family dinner every day or almost every day (5-6 times/week), whereas $21 \%$ had family dinner sometimes (3-4 times/week) and 16\% rarely ( $\leq 2$ times/week). The frequency of family dinners did not differ between the balanced and imbalanced school lunch eaters. However, the eating pattern at home was healthier among children who ate a balanced school lunch. Their family meals included vegetables in every meal $(P=0 \cdot 002)$; fruit was offered daily $(P=0 \cdot 007)$ and soft drinks were offered less often at home $(P=0 \cdot 006)$. The balanced school lunch eaters also took part in cooking more often $(P=0 \cdot 014)$ and their parents paid more attention to the quality of the diet $(P=0 \cdot 021)$. The availability of sweet or salty snacks at home and the possibility of influencing the type of food eaten at home did not differ between the groups.

\section{Food choices}

Only $34 \%$ of children ate rye bread or crisp bread, and $15 \%$ ate wheat bread $\geq 1$ time/d. Porridge was eaten at least 5 times/week by only $17 \%$ of the children. Altogether, $22 \%$ of the children ate vegetables and $23 \%$ ate fruit or berries every day. A total of $70 \%$ of the children drank milk or sour milk, $22 \%$ ate yoghurt with sugar and 9\% consumed natural yoghurt at least 5 times/week. Of the fast foods, pizzas and French fries or fried potatoes were eaten at least 1-2 times/week by 5\% of the children, and hamburgers, hot dogs or kebabs and meat pies or pastries were consumed by $6 \%$ of children. The consumption of other unhealthy products was quite common: $22 \%$ of the children ate candies or chocolate, $19 \%$ consumed buns, cookies or doughnuts, $16 \%$ consumed ice cream, 12\% consumed salty snacks and $11 \%$ ate puddings at least 2-4 times/week. Juice and hot chocolate were consumed 
Table 4 Usually consumed snacks among the balanced $(n$ 239) and imbalanced $(n$ 275) school lunch eaters

\begin{tabular}{|c|c|c|c|c|c|}
\hline & \multicolumn{2}{|c|}{ Balanced eaters } & \multicolumn{2}{|c|}{ Imbalanced eaters } & \multirow[b]{3}{*}{$P$ value } \\
\hline & Usual & Not usual & Usual & Not usual & \\
\hline & $\%$ & $\%$ & $\%$ & $\%$ & \\
\hline Bread & $68 \cdot 6$ & $31 \cdot 4$ & $62 \cdot 2$ & $37 \cdot 8$ & $0 \cdot 127$ \\
\hline Dairy products & $59 \cdot 4$ & $40 \cdot 6$ & $47 \cdot 6$ & $52 \cdot 4$ & 0.008 \\
\hline Fruit or berries & $59 \cdot 4$ & $40 \cdot 6$ & $42 \cdot 5$ & $57 \cdot 5$ & $<0.001$ \\
\hline Candies or chocolate & $24 \cdot 3$ & $75 \cdot 7$ & $31 \cdot 0$ & $69 \cdot 0$ & 0.074 \\
\hline Buns, cookies or doughnuts & $23 \cdot 0$ & $77 \cdot 0$ & $30 \cdot 5$ & $69 \cdot 5$ & 0.055 \\
\hline Soft drinks or energy drinks & $16 \cdot 0$ & $84 \cdot 0$ & $25 \cdot 0$ & $75 \cdot 0$ & 0.010 \\
\hline Ice cream & $16 \cdot 7$ & $83 \cdot 3$ & $20 \cdot 4$ & $79 \cdot 6$ & 0.293 \\
\hline Vegetables & $15 \cdot 0$ & $85 \cdot 0$ & $10 \cdot 2$ & $89 \cdot 8$ & 0.095 \\
\hline Salty snacks & $8 \cdot 0$ & $92 \cdot 0$ & $14 \cdot 5$ & $85 \cdot 5$ & 0.026 \\
\hline
\end{tabular}

${ }^{*}$ Frequencies were generated by cross-tabulations using the $\chi^{2}$ test for statistical significance.

Table 5 Frequencies of consumption of different foods among the balanced ( $n$ 231-239) and imbalanced $(n 258-266)$ school lunch eaters

\begin{tabular}{|c|c|c|c|c|c|c|c|c|c|}
\hline & \multicolumn{4}{|c|}{ Balanced eaters } & \multicolumn{4}{|c|}{ Imbalanced eaters } & \multirow{3}{*}{$P$ value } \\
\hline & \multicolumn{4}{|c|}{ Rarely 1 time/week 2} & \multirow{2}{*}{$\frac{\text { Rarely }}{\%}$} & \multirow{2}{*}{$\frac{1 \text { time/week }}{\%}$} & \multirow{2}{*}{$\frac{2-4 \text { times/week }}{\%}$} & \multirow{2}{*}{$\frac{\geq 5 \text { times/week }}{\%}$} & \\
\hline & $\%$ & $\%$ & $\%$ & $\%$ & & & & & \\
\hline Pizzas & $89 \cdot 1$ & $8 \cdot 0$ & $1 \cdot 7$ & $1 \cdot 2$ & $78 \cdot 2$ & $14 \cdot 7$ & $4 \cdot 5$ & $2 \cdot 6$ & 0.010 \\
\hline Meat pies or pastries & $88 \cdot 1$ & $9 \cdot 8$ & 0.4 & $1 \cdot 7$ & $81 \cdot 4$ & $8 \cdot 7$ & $6 \cdot 5$ & $3 \cdot 4$ & 0.022 \\
\hline Porridge & $35 \cdot 7$ & $32 \cdot 8$ & $13 \cdot 6$ & $17 \cdot 9$ & $47 \cdot 0$ & $25 \cdot 9$ & $9 \cdot 3$ & $17 \cdot 8$ & 0.045 \\
\hline Rye or crisp bread & $4 \cdot 8$ & $7 \cdot 3$ & $14 \cdot 3$ & $73 \cdot 6$ & $9 \cdot 3$ & $16 \cdot 7$ & $18 \cdot 6$ & $55 \cdot 4$ & $<0.001$ \\
\hline Milk or sour milk & $7 \cdot 3$ & $5 \cdot 2$ & $7 \cdot 8$ & $79 \cdot 7$ & $18 \cdot 6$ & $5 \cdot 8$ & $8 \cdot 1$ & $71 \cdot 5$ & 0.021 \\
\hline Yoghurt with sugar & $26 \cdot 3$ & $27 \cdot 6$ & $16 \cdot 8$ & $29 \cdot 3$ & $38 \cdot 4$ & $27 \cdot 9$ & $15 \cdot 9$ & $17 \cdot 8$ & 0.001 \\
\hline Ice cream & $53 \cdot 2$ & $34 \cdot 8$ & $6 \cdot 9$ & $5 \cdot 1$ & $45 \cdot 4$ & $32 \cdot 1$ & $12 \cdot 8$ & $9 \cdot 7$ & 0.014 \\
\hline
\end{tabular}

Consumption of hamburgers, hot dogs or kebabs, French fries or fried potatoes, wheat bread, natural yoghurt, pudding, ice cream, salty snacks, candies or chocolate, buns, cookies or doughnuts, hot chocolate and juice did not differ between the groups.

${ }^{*}$ Frequencies were generated by cross-tabulations using the $\chi^{2}$ test and in a few cases by the non-parametric version of the $\chi^{2}$ (i.e. Fisher's Exact test) for statistical significance.

daily by $16 \%$, soft drinks by $8 \%$ and energy drinks by $4 \cdot 4 \%$ of the children.

Eating a balanced school lunch was associated with healthier food choices (Table 5). The children who reported eating a balanced school lunch not only ate pizzas $(P=0 \cdot 010)$ and meat pies or pastries $(P=0 \cdot 001)$ less frequently but also drank soft drinks $(P=0 \cdot 004)$ and energy drinks $(P<0 \cdot 001)$ less often. The balanced school lunch eaters consumed porridge $(P=0 \cdot 045)$, rye bread or crisp bread $(P<0 \cdot 001)$, milk or sour milk $(P=0 \cdot 021)$, yoghurt with sugar $(P=0 \cdot 001)$, vegetables $(P<0 \cdot 001)$ and fruit or berries $(P<0.001)$ more often. The consumption of hamburgers, hot dogs or kebabs, French fries or fried potatoes, wheat bread, natural yoghurt, pudding, ice cream, salty snacks, candies or chocolate, buns, cookies or doughnuts, hot chocolate and juice did not differ between the groups. The frequencies of consumption of vegetables, fruit or berries, soft drinks and energy drinks are not presented in Table 5 , because of different consumption categories for these food items. Vegetables were eaten daily by $29.9 \%$ and fruit or berries by $30.4 \%$ of the balanced school lunch eaters, whereas the percentages among the imbalanced school lunch eaters were $18.6 \%$ and $19 \cdot 6 \%$, respectively. Vegetables and fruit or berries were eaten rarely by $36 \cdot 8 \%$ and $35 \cdot 3 \%$ of the imbalanced school lunch eaters, whereas among the balanced school lunch eaters only $17 \cdot 8 \%$ rarely consumed vegetables and fruit or berries. Soft drinks and energy drinks were consumed $\geq 5$ times/week by $5.6 \%$ and $1.7 \%$ of balanced school lunch eaters, whereas the respective percentages among the imbalanced school lunch eaters were $11 \cdot 3$ and $7 \cdot 4$.

\section{Discussion}

The present study suggests that eating a balanced school lunch is associated with overall healthier eating patterns. Children who ate a balanced school lunch seemed to eat more healthily both at school and at home, and they had a more regular meal pattern. Therefore, eating a balanced school lunch could be seen as an indicator of the overall eating pattern of young children and adolescents.

In the present study, only a minority of the children $(8 \cdot 8 \%)$ consumed all components of the school lunch offered as recommended by the Finnish National Nutrition Council. In other studies, the percentages have been somewhat higher; $10-35 \%$ of schoolchildren have reported 
eating all components (main dish, salad, bread with vegetable oil-based margarine and milk or sour milk) of the school lunch ${ }^{(25-27)}$. The reason for the lower percentages in the present study is not known; however, on the whole, it is surprising and somewhat alarming that a well-balanced school lunch offered in Finnish schools is not accepted by a high percentage of schoolchildren.

Because of the less number of children consuming a meal that fulfilled all criteria of a well-balanced school lunch, we modified the criteria in the present study so that those consuming the main dish, salad and bread almost every day were regarded as consuming a balanced school lunch. With this criterion the number of children in each group was more comparable, that is, $46.5 \%$ in the balanced group compared with $53.5 \%$ in the imbalanced group. An interesting finding was that even with these less-strict criteria clear differences in eating patterns and in the quality of the overall diet could be observed.

Only $41.5 \%$ of boys and $50.7 \%$ of girls usually ate a balanced school lunch. This is explained by the fact that girls ate salad more often compared with boys. The higher proportion of girls with a better diet is in accordance with the findings of other studies ${ }^{(28)}$. Raulio et al. ${ }^{(25)}$ observed that obese children ate school meals less often compared with children with normal growth. Skipping breakfast and not having dinner with the family in the evenings were also associated with less-frequent eating of school lunch. However, in our study, the balanced and imbalanced school lunch eaters did not differ in their prevalence of overweight or underweight. Body weight and height were self-reported, which may have reduced the reliability of the anthropometric data. Eating a family dinner did not differ between the balanced and imbalanced school lunch eaters, but the balanced school lunch eaters had healthier eating patterns at home and they ate breakfast more often. The age of the children had no effect on whether they ate a balanced or an imbalanced school lunch. Irrespective of age or weight, consuming a balanced school lunch is important for every child.

In order to persuade children to eat balanced lunches more often, schools need to continue to develop the content of the lunch offered, as well as the eating conditions. The most common reason for skipping school lunches was the fact that the children did not like the food offered. The school lunch menu should be planned according to children's taste preferences and the menu should be more variable. Many studies have reported that school lunches can promote healthy eating by making healthy choices easy during the school day ${ }^{(3,6,29)}$.

Moreover, one of the most common nutritional problems among children in relation to their diet is low consumption of vegetables, fruit and wholegrain products ${ }^{(5,6)}$. According to the present study, school lunches could offer a way of balancing the diet by serving a larger variety of breads, salads and vegetables. In addition, at least some of the vegetables could be provided as individual components instead of in a mixed salad. School lunches could also include more fruit in the form of desserts or as snacks. Increased availability of vegetables and fruit has been found to enhance their consumption ${ }^{(30)}$.

One common reason for skipping lunch that was reported by the participants in the present study was an unpleasant eating environment. This is something that schools should also pay more attention to. It is a wellknown fact that a pleasant eating environment and serving food in an attractive manner enhance enjoyment of the meal $^{(31)}$. Another quite common reason cited by children for skipping school lunches was that they were not hungry. Although the reason for this was not specified, it could be suggested that more attention should also be paid to scheduling of the lunch time. Another possible explanation for children not being hungry during lunch time might be that they consume snacks during the morning hours. For some of the children, the reason for skipping lunch was that their friends did not eat lunch either. Eating is a social occasion in which the eaters influence each other's eating behaviour and thereby the development of food preferences and eating pattern ${ }^{(32)}$.

Data were collected using Internet-based questionnaires that the children filled in at schools, with teachers assisting the children when needed. The response rates were very high, that is, $83 \%$. Moreover, as questionnaires were filled in at all primary and middle schools in Sotkamo, the data represent the dietary habits of the school-aged children in that part of Finland well. Of course, we cannot rule out the possibility that the results would have been different had the data been collected from some other area of Finland. However, there is no reason to make allowances for such a possibility. Moreover, the main findings were well in line with the earlier literature ${ }^{(3,5,6)}$. Instead, one of the major weaknesses of the study was that the data were only qualitative and we do not have quantitative information about how much the children actually eat. Collecting quantitative information in an accurate and reliable manner would, however, have made the study much more demanding for the children and, as a consequence, the response rates would likely have been lower.

In conclusion, the results of the present study indicate that school lunches consumed by children aged 11-16 years also reflect their overall eating patterns outside the school. Eating a balanced school lunch is associated with more regular meal patterns, the availability of healthier foods at home and an overall healthier diet, suggesting that healthy eating patterns are learnt at home. School lunch intake could thus be considered as a marker of overall dietary patterns, making it possible to identify those children at an increased risk for poor diet. The results also confirm earlier findings that Finnish schoolchildren rarely consume all components of a school lunch even though the lunch is freely offered. Future research is needed to clarify whether collaboration between schools and parents could contribute to the development of healthier eating patterns among school-aged children. 


\section{Acknowledgements}

Financial support for K.P. was provided by the Academy of Finland and for J.L. by the Raisio Plc Research Foundation. The authors have no conflict of interest to declare. T.T.-T. implemented the study and wrote the article; S.P., J.L. and L.K. assisted with data analyses and with writing of the manuscript; K.P. and H.M. assisted with study implementation and with writing of the manuscript. The authors thank the participants of the Liikkumisesta kansalaistaito project for making the study possible.

\section{References}

1. Finnish National Board of Education (2008) School meals in Finland, investment in learning. http://www.evira.fi/ attachments/vrn/school_meals_in_finland.pdf (accessed June 2010).

2. National Nutrition Council (2008) Kouluruokasuositus (Dietary Guidelines for School Meals). Helsinki: Savion kirjapaino Oy.

3. Raulio S, Roos E \& Prättälä R (2010) School and workplace meals promote healthy food habits. Public Health Nutr 13, 987-992.

4. Hastert TA \& Babey SH (2009) School lunch source and adolescent dietary behavior. Prev Chronic Dis 6A, 117-126.

5. Cohen DA, Sturm R, Scott M et al. (2010) Not enough fruit and vegetables or too many cookies, candies, salty snacks and soft drinks? Public Health Rep 125, 88-95.

6. Hoppu U, Lehtisalo J, Tapanainen H et al. (2010) Dietary habits and nutrient intake of Finnish adolescents. Public Health Nutr 13, 965-972.

7. Berkey C, Rockett H, Field A et al. (2004) Sugar-added beverages and adolescent weight change. Obes Res 12, 778-788.

8. Novotny R, Daida Y, Acharya S et al. (2004) Dairy intake is associated with lower body fat and soda intake with greater weight in adolescent girls. J Nutr 134, 1905-1909.

9. Phillips S, Bandini L, Naumova E et al. (2004) Energy-dense snack food intake in adolescence: longitudinal relationship to weight and fatness. Obes Res 12, 461-472.

10. Roseman M, Yeung WK \& Nickelsen J (2007) Examination of weight status and dietary behaviors of middle school students in Kentucky. J Am Diet Assoc 107, 1339-1345.

11. Hassapidou M, Fotiadou E, Maglara E et al. (2006) Energy intake, diet composition, energy expenditure, and body fatness of adolescents in Northern Greece. Obesity (Silver Spring) 14, 855-862.

12. Siega-Riz A, Carson T \& Popkin B (1998) Three squares or mostly snacks - what do teens really eat? J Adolesc Health 22, 29-36.

13. Roos E, Hirvonen T, Mikkilä V et al. (2001) Household educational level as determinant of consumption of raw vegetables among male and female adolescents. Prev Med 33, 282-291.

14. Lien N, Jacobs D \& Klepp K-I (2002) Exploring predictors of eating behavior among adolescents by gender and socio-economic status. Public Health Nutr 5, 671-681.

15. Vågstrand K, Barkeling B, Forslund HB et al. (2007) Eating habits in relation to body fatness and gender in adolescents results from the 'SWEDIS' study. Eur J Clin Nutr 61, 517-525.
16. Gillman MW, Rifas-Shiman SL, Frazier AL et al. (2000) Family dinner and diet quality among older children and adolescent. Arch Fam Med 9, 235-240.

17. Neumark-Sztainer D, Hannan PJ, Story M et al. (2003) Family meal patterns: associations with sociodemographic characteristics and improved dietary intake among adolescents. J Am Diet Assoc 103, 317-322.

18. Utter J, Scragg R, Schaaf D et al. (2008) Relationships between frequency of family meals, BMI and nutritional aspect of the home food environment among New Zealand adolescents. Int J Beh Nutr Phys Act 23, 50.

19. Sen B (2006) Frequency of family dinner and adolescent bodyweight status. Evidence from the National Longitudinal Survey in Youth, 1997. Obesity (Silver Spring) 14, 2266-2276.

20. Tavernas EM, Rifas-Shiman S, Berkey C et al. (2005) Family dinner and adolescent overweight. Obes Res 13, 900-906.

21. World Health Organization (2008) Health Behavior of School Aged Children study (HBSC). http://www.euro.who.int/data/ assets/pdf_file/0005/53852/E91416.pdf (accessed March 2011).

22. Finnish National Institute for Health and Welfare (2008) The School Health Promotion Study (SHP). http://info.stakes.fi/ NR/rdonlyres/A076F448-9125-4EFE-8163-82724304D971/ 0/SHPS_questionnaire_2008.pdf (accessed March 2011).

23. Cole TJ, Bellizzi MC, Flegal KM et al. (2000) Establishing a standard definition for child overweight and obesity worldwide: international survey. BMJ 320, 1240-1243.

24. Centers for Disease Control and Prevention (2008) About BMI for children and teens. http://www.cdc.gov/healthyweight/ assessing/bmi/childrens_bmi/about_childrens_bmi.html (accessed February 2011).

25. Raulio S, Pietikäinen M \& Prättälä R (2007) Suomalaisnuorten Kouluaikainen Ateriointi (Eating Habits of Finnish Schoolchildren During School Hours). Publication of the National Public Health Institute, B26/2007. Helsinki: National Public Health Institute; available at http:// www.ktl.fi/attachments/suomi/julkaisut/julkaisusarja_b/2007/ 2007b26.pdf

26. Hoppu U, Kujala J, Lehtisalo J et al. (editors) (2008) Yläkoululaisten Ravitsemus ja Hyvinvointi. (Nutrition and Well-being of Secondary School Pupils). Publications of National Public Health Institute B30/2008. Helsinki: Edita Prima Oy; available at http://www.ktl.fi/attachments/ suomi/julkaisut/julkaisusarja_b/2008/2008b30.pdf

27. Urho U-M \& Hasunen K (2004) Yläasteen Kouluruokailu (School Catering in the Upper Level of the Comprehensive School in 2003). Helsinki: Edita Prima Oy; available at http://pre20090115.stm.fi/pr1075974689098/passthuru.pdf

28. Mikkilä V, Räsänen L, Raitakari OT et al. (2005) Consistent dietary patterns identified from childhood to adulthood: the cardiovascular risk in Young Finns Study. Br J Nutr 93, 923-931.

29. Institute of Medicine (2007) Nutrition Standards for Foods School: Leading the Way Toward Healthier Youth. Washington, DC: National Academies Press.

30. Hoffman JA, Franko DL, Thompson DR et al. (2010) Longitudinal behavioral effects of school-based fruit and vegetable promotion program. J Pediatr Psychol 35, 61-71.

31. Wansink B (2004) Environmental factors that increase the food intake and consumption volume of unknowing consumer. Annu Rev Nutr 24, 455-479.

32. Birch LL \& Fisher JO (1998) Development of eating behaviors among children and adolescents. Pediatrics 101, 539-549. 